Scientific Review - Engineering and Environmental Sciences (2018), 27 (4), 536-551

Sci. Rev. Eng. Env. Sci. (2018), 27 (4)

Przegląd Naukowy - Inżynieria i Kształtowanie Środowiska (2018), 27 (4), 536-551

Prz. Nauk. Inż. Kszt. Środ. (2018), 27 (4)

http://iks.pn.sggw.pl

DOI 10.22630/PNIKS.2018.27.4.50

Sugiono SUGIONO, Remba Y. EFRANTO, Andhika R. BUDIPRASETYA

Faculty of Engineering, Brawijaya University

\title{
Reducing musculoskeletal disorder (MSD) risk of wiring harness workstation using workplace ergonomic risk assessment (WERA) method
}

Key words: wiring harness, work posture, musculoskeletal disorder (MSD), workplace ergonomic risk assessment (WERA)

\section{Introduction}

Musculoskeletal disorder (MSD) is a major complaint experienced by workers in various fields that will be fatal if not immediately investigated further. The effects of MSDs sometimes do not emerge immediately and will be felt when workers begin stepping the old age, such as degenerative disc disease, tension neck syndrome, and ruptured disc. Many studies have been done on MSD risks in various occupations such as nurses, farmers, machine operators, office workers and so on (Alexopoulos, Stathi \& Charizani, 2004; Fjell, Alexanderson, Karlqvist \& Bildt, 2007; Baek, Kim \& Yi, 2015; Shariat, Mohd Tamrin, Arumugam, Danaee \& Ramasamy, 2016). MSDs can be generated by several causes such as pro- longed duration of working, overwork, unsuitable work postures, repetitive work, poor nutrition and hydration. Sugiono, Soenoko \& Andriani (2017) and Sugiono, Soenoko \& Lukodono (2017) in their articles noted that the ergonomic science approach - a science studying the relationship between humans, machines/equipment and work environment to achieve comfort levels of work that do not negatively impact human psychology and physical - can be utilized to minimize the presence of MSDs.

Wiring harness companies are companies that focus on making the electrical system of various kinds of car brands. In general, the wiring harness production is divided into two parts, namely pre-assembly which is the wire preparation stage such as cutting, crimping, and bonding before being put together with other wires and final assembly which is the unification stage of the wire parts. Some companies use a lot of human power, i.e. women workers, especially in 
the final assembly activities. According to the survey results of some workers of wiring harness manufactures, the types of jobs that most often lead to a risk of bodily injury and soreness are torque job (making car battery circuits), grommet job (adding water-resistant compartment using expander grommet machines), and offline job (installing accessories - clip) for the attachment parts on cars).

According to the results of operators' discomfort survey, parts of the body that most often suffer pain are shoulders, neck, hands and calves. This is because the operators rely heavily on the upper body to do their works repeatedly while the calves function to support the operator's body for $8 \mathrm{~h}$. On the other side, parts of the body that do not experience pain or fatigue at most are hips, thighs, elbows, and knees. The severity of pain complained by the operators on the scale of 5 are that occurring in neck, calves, and upper back, indicating that the pain is at a medium level in which if it is allowed to happen continuously, the pain will increase to the next level. The pain occurs because the neck and back are allowed to bend down too often and the calves sustain the body for a long duration. Some operators also feel pain on the scale of 8-9 stating that the pain can be categorized into a high level, which usually occurs in hands, shoulders and legs. The high level of pain in the hands, shoulders, and legs is also caused by repetitive movements and poor work postures performed for $8 \mathrm{~h}$.

There are many methods to assessment the MSD such as rapid upper limb assessment (RULA), job strain index (JSI), rapid entire body assessment (REBA), baseline risk of ergo- nomics factor (BRIEF), ergonomics assessment survey method (EASY), quick exposure checklist (QEC), OVAKO working analysis system (OWAS), workplace ergonomic risk assessment (WERA), assessment of repetitive tasks (ART) tool, etc. The WERA method is selected according to content of assessment including complete human postures, repetition task, vibration, force/ /strength exertion, contact stress, and task duration. This method fits perfectly with the type of work on Wiring harness companies that is done in a standing position, carrying loads, assembly, repetitive work and bending.

The WERA method can be used to identify the types of occupations with the highest risk of MSDs (Abd Rahman, Abdul Rani \& Rohani, 2011). WERA provides a rapid job task screening method for exposing physical risk factors associated with work-related musculoskeletal disorders. WERA assessment consists of six physical risk factors including posture, repetition, strength/force exertion, vibration, contact stress, and task duration, which involves 5 major body parts: shoulders, wrists, back, neck and legs (Abd Rahman et al., 2011).

The research was looking for the best working posture to wire harness employees based on WERA assessment. As consequence, output of the research possibly recommended to redesign the workstations. The final result of the assessment using WERA reflects action levels showing how potential MSDs are in the assessed work. The achieved objectives are to conduct an action level assessment using WERA method, to provide improved work postures, to build good work system especially for the jobs potentially 
triggering MSDs, and to provide a comparison of WERA scores before and after the attempts of reducing the risks of MSDs. WERA assessment is expected to provide improvement recommendations that are in line with the problems observed in wiring harness companies.

\section{Research method}

This research belonged to a descriptive research, describing the emerging problems in the activities of workers in wiring harness companies associated with workers' health due to improper work postures or movement. The existing facts served as a reference for solving problems based on scientific methodological principles to illustrate the relationship between working conditions and workers' health, particularly on MSDs. Field Study methods were used to collect data directly in which the researchers went directly to the research location in some wiring harness companies. The methods used in the field study are as follows:

a) Observation: a method used to obtain data by way of observing directly the actual situation in the company.

b) Interview: a question-and-answer session with the workers and the person in charge to know the problems further.

Data collection is the recording of information, description or characteristics of some or all elements of the population that support and facilitate research. The data used for this research are as follows:

a) Primary data, referring to data obtained directly from the research object and observed at the location of research implementation. The data were obtained through direct observation and work recording during the activity. The data were then inserted into the worksheet of WERA assessment including postures (shoulders, wrists, back, neck, and legs), repetition, vibration, force/strength exertion, contact stress, and task duration.

b) Secondary data, referring to data that had been available or presented by the company where this research took place, covering the company vision-mission, organizational structure, history, overview, tools/equipment used, processing procedures of torque, grommet, and offline jobs as well as a list of employees working on the torque, grommet, and offline sections.

Steps to identify MSD risks or hazards on workers of the wire harness company are as follows (Fig. 1):

a) Identifying each task on the existing postures in the job based on the work procedures. This activity was done accordingly with the work procedures that had been obtained from the observed company.

b) Measuring the angle of the postures formed on each task seen from the work recording. The angle measurement was done on the postures of the body parts assessed starting from the back where the spine is the main axis.

c) Conducting WERA assessment based on the postures formed on each task and other information required for WERA. There are 9 physical risk factors assessed (covering shoulders, wrists, neck, back, legs, force/ 


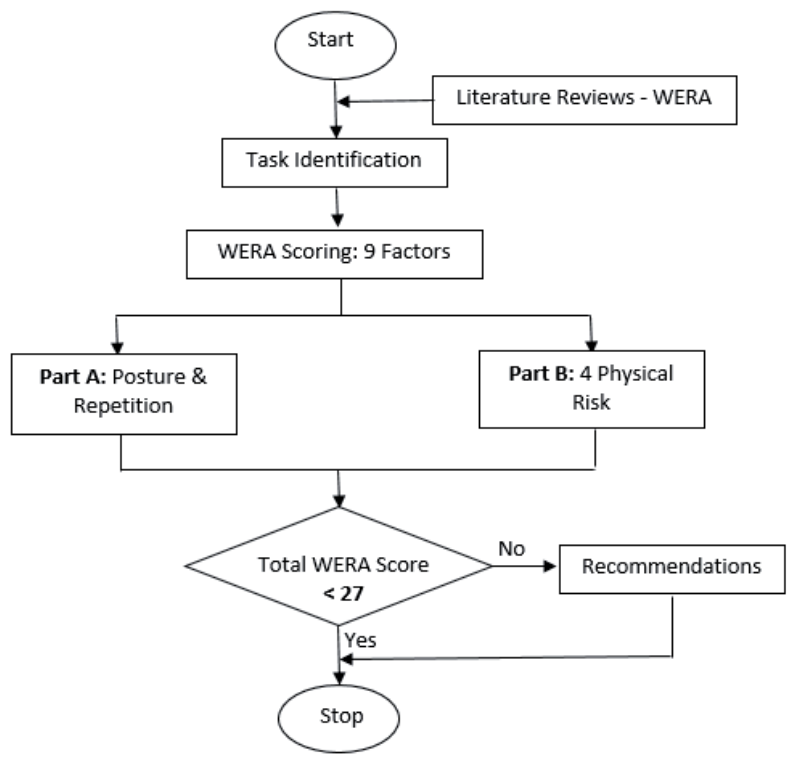

FIGURE 1. Flowchart of research steps for WERA method

/strength exertion, vibration, contact stress, and task duration), which is explained further as follows:

- risk factor assessment of shoulders. The shoulder factor assessment consists of shoulder postures and shoulder repetition.

- risk factor assessment of wrists. The wrist factor assessment consists of wrist postures and wrist repetition.

- risk factor assessment of back. The back factor assessment consists of back postures and back repetition.

- risk factor assessment of neck. The neck factor assessment consists of neck postures and neck repetition.

- risk factor assessment of legs. The leg factor assessment consists of leg postures and work duration.

- risk factor assessment of force exertion. The force exertion factor assessment consists of the load lifted and back postures.
- risk factor assessment of vibration. The vibration factor assessment consists of the vibration exposure duration on the tools or instruments used and wrist postures.

- risk factor assessment of contact stress. The contact stress factor assessment consists of the use of tool grip or gloves and wrist postures.

- risk factor assessment of task duration. The work duration factor assessment consists of the duration of work or task and the load lifted. Each of the 9 physical risk factors mentioned above has a score to be then summed up with all the assessed physical risk factors.

d) Classifying risk level based on WERA score as explained in Table 1. If the job is categorized in low risk level then stop the investigation, but if the total final WERA score categorized in medium or high risk level (Fig. 1, WERA score > 27) then de- 
sign some recommendations (go to step f).

e) Identifying tasks and sections from 9 factors to find dominant contribution in WERA score, in this case, the recommendation is indicated by WERA score $>4$.

f) Design the recommendation based on step e.

The research investigated 3 jobs in wiring harness factory, there were torque job, expander grommet job and offline job, each of which involved 3 operators (totally $=9$ workers). Basically, the factory works in one shift for normal condition and will operate 2 shifts work if a lot of orders come to the factory. As consequence, the researchers observed one shift of work on the morning shift which is starting from 07.30 to 16.00 . The shift has 3 breaks time; 2 short breaks of $15 \mathrm{~min}$ and hour-lunch break, so the total break time is $1.5 \mathrm{~h}$.

Posture data were obtained by shooting or capturing pictures of the operators during their working using a handy camera, and working procedures needed to adjust the positions of the images taken and the jobs done. The identification of the tasks on the wiring harness jobs covered three categories. The first was the identification of torque job tasks. The operators of this job were in charge of making the car battery circuit using automatic bolt fasteners to tighten the end of the circuit. The operators installed 10-sized nuts 4 times on 4 circuits in 1 work cycle. The second was the identification of expander grommet job tasks. The operators of this job were in charge of installing grommets or protective compartments of wiring harness made of rubber with a length of $27 \mathrm{~cm}$ and a diameter of $10 \mathrm{~cm}$ to protect wiring harness from water assisted by an expander grommet machine. The grommet installation was done twice at one time. The last was the identification of offline job tasks. The operators of this job were responsible for checking the clip 11 times and inspecting the additional 15.5 centimeter-sized clip installation 10 times as well as well as doing taping to bind inter-circuit assisted with a clip gun and insulation.

\section{Results and discussion}

There are 3 main jobs will be analyzed in this research, which are torque job, expander grommet job, and offline job. Following is an example of calcu-

TABLE 1. Three classes risk level based on total WERA score (Abd Rahman et al., 2011)

Action Level
\begin{tabular}{|c|c|l|c|}
\hline Risk Level & Final Score & \multicolumn{1}{|c|}{ Action } & Tick (v) \\
\hline LOW & $18-27$ & Task is acceptable & $\square$ \\
\hline MED & $28-44$ & $\begin{array}{l}\text { Task is need to further } \\
\text { investigate \& required } \\
\text { change }\end{array}$ & $\square$ \\
\hline HIGH & $45-54$ & $\begin{array}{l}\text { Task is not accepted, } \\
\text { immediately change }\end{array}$ & $\square$ \\
\hline
\end{tabular}


lation the WERA score for $1^{\text {st }}$ operator torque job (from 3 operators) which worked in 7 steps as explained on the research methodology and flowchart in Figure 1. The same ways, 2 operators of torque job, 3 operators of expander Grommet job and 3 operators of offline job will be calculated to find out the final WERA score. By knowing the work attitude of the operators in doing their jobs, posture assessment was then conducted to determine whether the work attitude performed by the operators was dangerous or not. The WERA assessment results of each assessed job were then compared one to another and then the largest risk factor equation would be searched to be analyzed.

The WERA assessment on the torque job was conducted by measuring or providing the angles formed by the work postures of the torque operators. Based on the observation, the torque job was divided into 59 work elements (tasks) which has different activities and posture positions. The grommet job was divided into 23 tasks and the offline job divided into 57 tasks. Figure 2 shows 3 example of $1^{\text {st }}$ activity, $2^{\text {nd }}$ activity and $10^{\text {th }}$ activity for torque job. The angle measurement was based on the human bone structure starting from the spine as the main axis.

Following is an example of how to calculate WERA score for torque job, $1^{\text {st }}$ operator and $2^{\text {nd }}$ task. The first assessment was undertaken on the shoulder posture as seen in Table 2 where the operator formed an upwards angle of $20.64^{\circ}$ or, in other words, the shoulder bent upwards. Therefore, it was said that the shoulder posture had a medium level (medium-score). Furthermore, on the repetition assessment, this task was given a heavy score because the shoulders unceasingly made a movement to insulate the harness. Additionally, on the scoring system, the assessment of both medium posture and high/heavy repetition reached a score of 5 .

The second assessment was carried out on the wrist posture as seen in Table 3 where the operator formed upwards and downwards angles of $25.21^{\circ}$ or, in other words, the hands bent upwards and downwards but not too extreme. Therefore, it
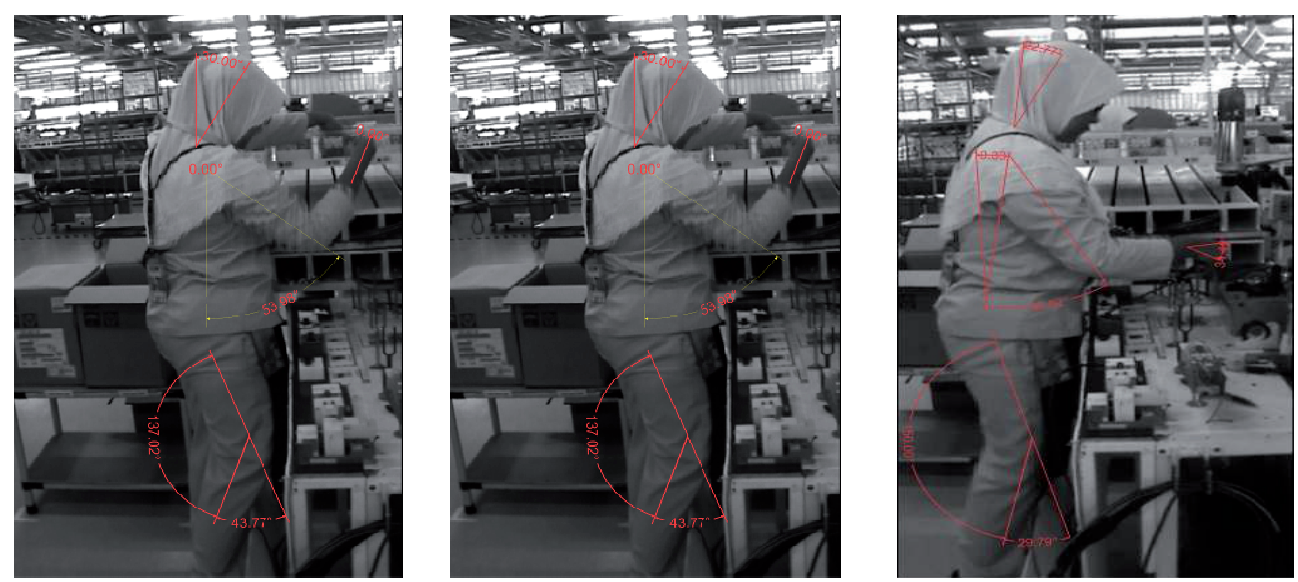

FIGURE 2. Work position of the torque job, $1^{\text {st }}$ operator for $1^{\text {st }}, 2^{\text {nd }}$ and $10^{\text {th }}$ activities tasks 
TABLE 2. WERA assessment of shoulder risk factor on torque job

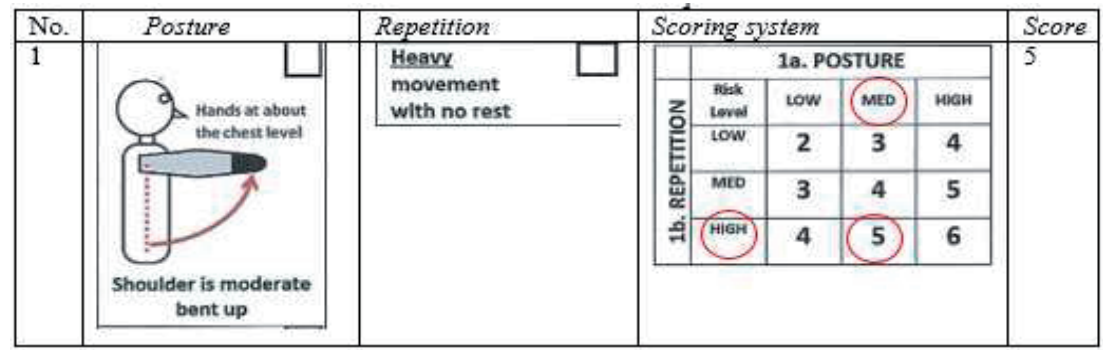

was said that the wrist posture was at a medium level or score. Meanwhile, the repetition assessment of this task was 20 times per minute because the hand constantly moved to insulate the harness, indicating a medium score. As for the scoring system, it was obtained a score of 4 from the assessment of both medium posture and medium repetition.

The third assessment was performed on the back posture as seen in Table 4 where the operator formed a forward back angle of $6.96^{\circ}$ and the back was in the medium position to bend and insulate the harness. Furthermore, on the repetition assessment, this task was given a low score because the back was only slightly moving. Meanwhile, on the scoring system, the assessment of medium posture and low repetition obtained a score of 3 .

As seen in Table 5, the fourth assessment was done on the neck posture where the operator formed a forward neck angle of $38.72^{\circ}$ or, in other words, the neck bent forward extremely. Thus, it was indicated that the neck posture was highly scored. In addition, the repetition assessment of this task was given a light score because the neck was just a little moving. As for the scoring system, it was achieved a score of 4 from the assessment of both high posture and low repetition.

The fifth assessment was performed on the leg posture as presented in Table 6 where the operator formed a neutral leg angle so that the leg posture was low rated. In contrast, the work duration assessment of this task was given a high score due to the $8 \mathrm{~h}$ of working. Meantime, on the scoring system, a score of 4 was obtained from the assessment of both low posture and high task duration.

The sixth assessment was undergone on the force exertion (the load lifted) as viewed in Table 7 where the operator

TABLE 3. WERA assessment of wrist risk factor on torque job

\begin{tabular}{|c|c|c|c|c|c|c|c|c|}
\hline No. & Posture & Repetition & \multicolumn{5}{|c|}{ Scoring system } & Score \\
\hline \multirow[t]{5}{*}{2} & \multirow{5}{*}{$\begin{array}{l}\text { Wrists are moderate } \\
\text { bent up or bent } \\
\text { down }\end{array}$} & \multirow{5}{*}{$\begin{array}{l}11-20 \text { times } \\
\text { per minute }\end{array}$} & & \multicolumn{4}{|c|}{ 2a. POSTURE } & 4 \\
\hline & & & z & $\begin{array}{l}\text { Rish } \\
\text { Lovol }\end{array}$ & Low & MED & HIGH & \\
\hline & & & है & Low & 2 & 3 & 4 & \\
\hline & & & $\frac{\vec{a}}{\vec{\alpha}}$ & (MED) & 3 & 4) & 5 & \\
\hline & & & คี & & 4 & 5 & 6 & \\
\hline
\end{tabular}


TABLE 4. WERA assessment of back risk factor on torque job

\begin{tabular}{|c|c|c|c|c|c|c|c|c|}
\hline No. & Posture & Repetition & \multicolumn{5}{|c|}{ Scoring system } & Score \\
\hline \multirow[t]{6}{*}{3} & & $0-3$ times & \multirow{5}{*}{ 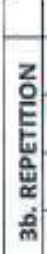 } & \multicolumn{4}{|c|}{ 3a. POSTURE } & 3 \\
\hline & & per minute & & $\operatorname{Rin}$ & Low & MED & Meล & \\
\hline & & & & (Low) & 2 & & 4 & \\
\hline & & & & MED & 3 & 4 & 5 & \\
\hline & i & & & HIGH & 4 & 5 & 6 & \\
\hline & $\begin{array}{l}\text { Back is moderate } \\
\text { bent forward }\end{array}$ & & & & & & & \\
\hline
\end{tabular}

TABLE 5. WERA assessment of neck risk factor on torque job

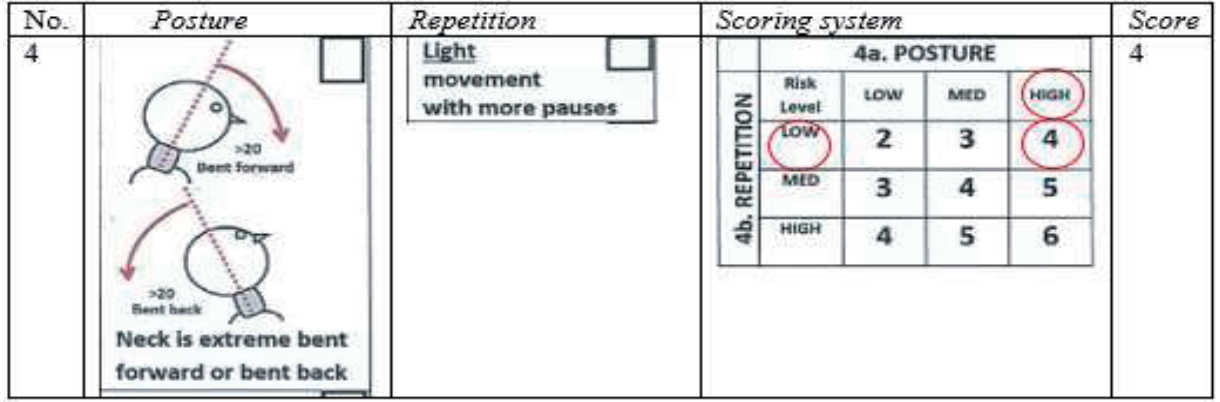

only lifted the insulation, indicating that the load lifted was still below $5 \mathrm{~kg}$ so it was given a low score. Furthermore, the previous assessment on the back posture had been given the medium score while the scoring system showed that the assessment of low lifted load and medium back posture obtained a score of 3 .
The seventh assessment was performed on the use of vibration tools. In doing this task, the operator did not use vibration tools so that the vibration was rated low while the previous assessment of the wrist posture was given the medium score. Thus, on the scoring system, it was obtained a score of 3 from

TABLE 6. WERA assessment of leg risk factor on torque job

\begin{tabular}{|c|c|c|c|c|c|c|c|c|}
\hline No. & Posture & Duration & \multicolumn{5}{|c|}{ Scoring system } & \multirow{3}{*}{$\frac{\text { Score }}{4}$} \\
\hline \multirow[t]{6}{*}{5} & \multirow{6}{*}{$\begin{array}{l}\text { Legs in neutral } \\
\text { position } \\
\text { OR } \\
\text { sittine with teet are } \\
\text { flat on floor / foot } \\
\text { rent. }\end{array}$} & \multirow{6}{*}{$>$ 4hrs per day } & & \multicolumn{4}{|c|}{ 5a. POSTURE } & \\
\hline & & & 7 & $\begin{array}{l}\text { Shitk } \\
\text { tovol }\end{array}$ & fow & MED & Н16н & \\
\hline & & & 읍 & Low & 2 & 3 & 4 & \\
\hline & & & $\frac{\text { ก๊ }}{5}$ & MED & 3 & 4 & 5 & \\
\hline & & & ต่ & (HiGH) & & 5 & 6 & \\
\hline & & & & & & & & \\
\hline
\end{tabular}


TABLE 7. WERA assessment of force exertion risk factor on torque job

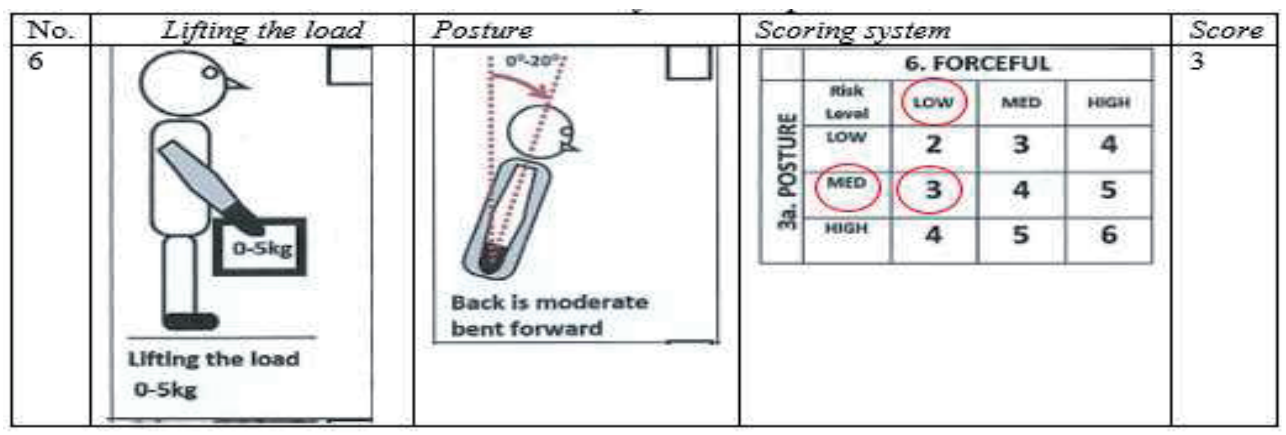

the assessment of low vibration tool and medium wrist posture. Furthermore, the eighth assessment was undertaken on the use of tool grip or gloves. It was found that the operator never used gloves while working so that a high score was given. Besides, the previous assessment of the wrist posture was given the medium score. Therefore, on the scoring system, a score of 5 was achieved from the assessment of both the high use of gloves and medium wrist posture. As for the ninth assessment performed on the task duration, it was found that the operator worked for $8 \mathrm{~h}$ so that the task duration risk factor was given a high score. In addition, the previous assessment on the load lifted showed a low score because the insulation load was not up to $5 \mathrm{~kg}$. Thus, the scoring system from the assessment of both the high work duration and low lifted load resulted in a score of 4 .

Based on the assessment results explained above, the WERA score for torque job, $1^{\text {st }}$ operator and $2^{\text {nd }}$ task has a total final score of 35 or indicating in a medium risk level. Furthermore, this job needed further investigation and improvements. Table 8 shows the average value of nine factors, 59 tasks for each torque job operator and an average of
WERA score for all (3) torque job operators. Overall the torque job has final WERA score $=31.23$ or is classified in medium risk level. According to Table 2, there are 3 factors of leg, contact stress and task duration significantly contributed WERA score with value more than 4 .

The calculation of WERA scores on the grommet operators and offline workers was similar to the calculation of the torque job described above. In the grommet job, the average score of the risk factor assessment obtained a scale of 2-6. This type of job had the highest risk factor score on the leg and task duration risk factor assessment, reaching a score of 4 . In the leg and task duration risk factors, the high score was influenced by the operator's work duration of $8 \mathrm{~h}$ per day, which indirectly required the operator to stand for $8 \mathrm{~h}$ and resulted in a high-risk factor category. The parts of the body obtained the risk factor score of $>3$ were shoulders, back and neck. In the risk factor of the operator's shoulders, back, and neck, the assessment showed low and medium scores because the job required the operator to bend and use his arms to draw the harness. Meanwhile, the wrist, force exertion, and contact stress risk factors had the lowest score because in 
TABLE 8. Average of WERA score in 9 factors for torque job

\begin{tabular}{|l|c|c|c|c|c|c|c|c|c|c|}
\hline \multirow{2}{*}{ Operator } & \multicolumn{9}{|c|}{ Risk factor } \\
\cline { 2 - 13 } & shoulder & wrist & back & neck & leg & forceful & vibration & $\begin{array}{c}\text { contact } \\
\text { stress }\end{array}$ & $\begin{array}{c}\text { task } \\
\text { dura- } \\
\text { tion }\end{array}$ & $\begin{array}{c}\text { final } \\
\text { score }\end{array}$ \\
\hline Torque 1 & 3.25 & 3.59 & 2.63 & 3.46 & 4.12 & 2.63 & 3.19 & 5.12 & 4.00 & 31.98 \\
\hline Torque 2 & 3.34 & 3.02 & 2.83 & 3.15 & 4.00 & 2.83 & 2.95 & 4.88 & 4.00 & 31.00 \\
\hline Torque 3 & 3.25 & 3.39 & 2.83 & 3.07 & 4.00 & 2.44 & 2.90 & 4.83 & 4.00 & 30.71 \\
\hline Average & 3.28 & 3.33 & 2.76 & 3.23 & 4.04 & 2.63 & 3.01 & 4.94 & 4.00 & 31.23 \\
\hline
\end{tabular}

doing the job, the operator rarely formed a bending wrist posture to draw the harness and the harness load was no more than $5 \mathrm{~kg}$. In addition, the operator did not wear gloves during the working. After processing the average WERA score, it was obtained a final score of 28.87 , indicating that the risk factor was at the medium level and the job needed further investigation and improvements.

Based on the average calculation of WERA scores on the offline job, the greatest risk factors were on the legs, contact stress and task duration where the operator worked for $8 \mathrm{~h}$ per day, leading the risk factor assessment to a high score. Moreover, the operator did not wear gloves during the working, causing the risk factor of the contact stress and task duration obtain a score of $>4$. As for the shoulder and neck risk factor assessment, the scores of both were $>3$ because the operator performed repetitive movements on his arms in taping, and the operator had to bend several times to see the object to be subjected to treatment. The risk factors with a score of $>2$ were on the wrists, back, force exertion, and vibration. On the wrist and back, the risk factor was given a low score because odd postures were more done on the neck and shoulder risk factors. On the other side, the force exertion and vibration risk factors were low rated due to the facts that the load lifted by the worker was no more than $5 \mathrm{~kg}$ and the operator of this job did not use tools causing vibration. After being calculated for the average, it was obtained that the final score reached 30.93 , indicating that the risk factor was at the medium level or, in other words, the job needed further investigation and changes or improvements.

Table 9 explains the summary of physical risk based on the WERA score for each factor for torque, gromet, and offline jobs. The results of the WERA score calculation indicated that the final scores of all three jobs studied were at the medium level. Its mean that all the job need to redesign for reducing the total WERA score to gain low risk level. The contact stress has the highest WERA score with score of 4.94 for torque job, 4.67 for offline job. The leg factor has WERA score of 4.04 for torque job, 4.00 for grommet job and 4.07 for offline job. The task duration has WERA score of 4.00 for all jobs.

The results of the WERA score calculation indicated that the final scores of all three jobs studied were at the medium level. That was, further investigation and improvements were needed. Here is an 
TABLE 9. Summary of physical risk based on WERA score for each factor for torque, grommet, dan offline jobs

\begin{tabular}{|c|c|c|c|}
\hline \multirow{2}{*}{ Specification } & \multicolumn{3}{|c|}{ WERA score } \\
\hline & $\leq 3$ & $3-4$ & $\geq 4$ \\
\hline Torque & $\begin{array}{l}\text { - back } \\
\text { - force exertion }\end{array}$ & $\begin{array}{l}\text { - shoulder } \\
\text { - wrist } \\
\text { - neck } \\
\text { - vibration }\end{array}$ & $\begin{array}{l}\text { - leg } \\
\text { - contact stress } \\
\text { - task duration }\end{array}$ \\
\hline Grommet & $\begin{array}{l}\text { - wrist } \\
\text { - force exertion } \\
\text { - vibration } \\
\text { - contact stress }\end{array}$ & $\begin{array}{l}\text { - shoulder } \\
\text { - back } \\
\text { - neck }\end{array}$ & $\begin{array}{l}\text { - leg } \\
\text { - task duration }\end{array}$ \\
\hline Offline jobs & $\begin{array}{l}\text { - wrist } \\
\text { - back } \\
\text { - force exertion } \\
\text { - vibration }\end{array}$ & $\begin{array}{l}\text { - shoulder } \\
\text { - neck }\end{array}$ & $\begin{array}{l}\text { - leg } \\
\text { - contact stress } \\
\text { - task duration }\end{array}$ \\
\hline
\end{tabular}

explanation of the improvements needed to be conducted in this research. Sequentially, recommendations are deigned first for contact stress factor and then leg factor and the latest is for duration factor.

\section{Prevention methods}

\section{Reducing contact stress}

According to some references (Dianat, Haslegrave \& Stedmon, 2014; Mylon, Buckley-Johnstone, Lewis, Carré \& Martin, 2015), the problem of contact stress can be eliminated or reduced by using gloves. Based on the observation, One of the reasons why the operators did not use gloves was that many of the operators felt slippery holding the circuit or even could not feel the circuit. According to a study from Occupational Safety and Health Administration (Tetrick \& Peiró, 2012 ), the statistics suggest that $70 \%$ of workers who experience hand injuries during manufacturing operations do not wear gloves. The other $30 \%$ hand injuries are caused by inadequate, defective or misused hand protection. There are several materials (Superiorgloves) that can be used for gloves adjusted to the type of industry e.g. polyurethane (PU), nitrile, foam nitrile, micropore nitrile, PVC and latex. The PU gloves is used for aerospace industry and appliance manufacturing, nitrile gloves is used for general industry carpentry, foam nitrile and micropore nitrile is used for metal fabrication and automotive assembly, PVC gloves is used for furniture manufacturing, and the latex gloves is used for glass manufacturing and construction.

The recommendation is replacing the existing material of gloves from nylon to foam nitrile because this material suits the industry of automotive assembly parts and has a good or strong grip. Moreover, the thickness of this type of gloves is 4-miles or $0.1016 \mathrm{~mm}$, which is thin enough to feel the circuit (Fig. 4). The goves will reduce the WERA score from score of $>4$ to be score of $\approx 2.63$ (same with gromet job which used gloves). 


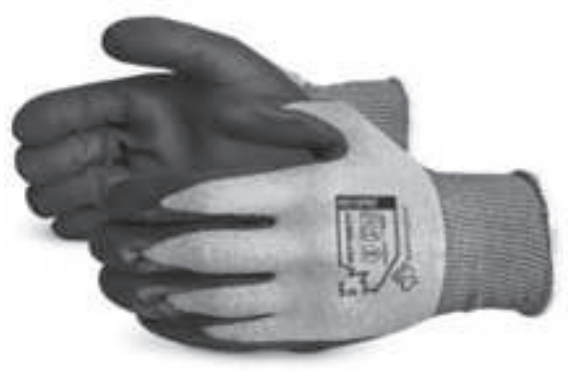

FIGURE 4. Gloves made of foam nitrile for wiring harnes factory

\section{Reducing leg risk}

Another problem existing in this job was the standing activity performed for a long time. Making a sit-and-stand up designed workplace was very unlikely at that time because the company's work procedures required the workers/ operators to stand during working and they only could sit or take a rest during the break time. However, an additional support on feet (footrest) is possible to reduce fatigue in the legs during working. Moreover, Konz and Johnson (2004) stated that when the legs are on the rail or footrest, the large back muscles beside the body will be relaxed and receive blood flow (carrying nutrients and disposing of useless products). Although this kind of improvement could not decrease the WERA score, it was expected that this could make the operators felt comfortable in working. Figure 5 is an example of footrest needed to be proposed.

\section{The other recommendation: neck and shoulder working postures}

Based on the final WERA scores, the physical risk factors with the highest score were neck and shoulders. Therefore, in this part, it should be done

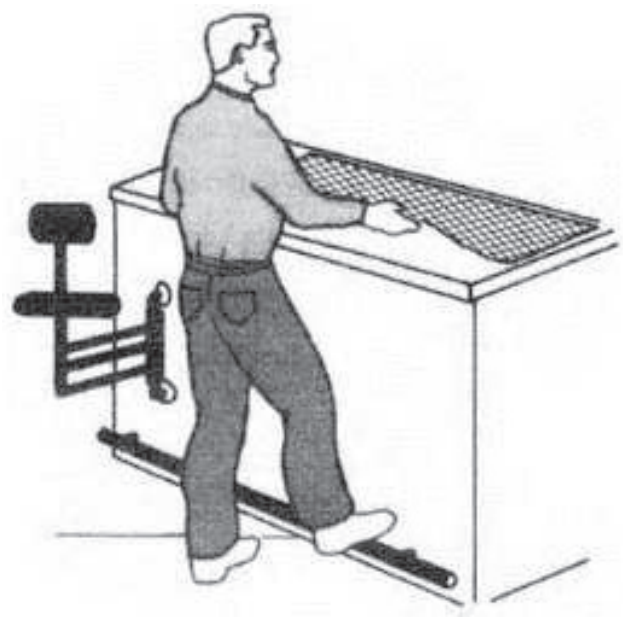

FIGURE 5. Footrest bar at work station for reducing fatique on leg

workstation redesign on the torque job in order to reduce the WERA score of the body parts. At the torque workstation, there was a table with a length of $170 \mathrm{~cm}$, width of $70 \mathrm{~cm}$, and height of $105 \mathrm{~cm}$ used by the operator in doing his work. It is known that in the workstation today, operators often bend over to see the object due to the table position that is too short, and the shoulder position required to bend upwards when performing tasks in the section close to the operator. This causes the results of the physical risk factor assessment on the neck and shoulders become high. Therefore, the improvement made for this situation in this research was to make a table with the slope accordingly with the operator's head so that the operator's neck and shoulder postures would be low rated. The data used in redesigning the workstation are those from the Indonesian Anthropometry due to the limitation of the operator's anthropometric data collection in which the data are filtered with the criteria such as coming from the Java tribe, women, 
and 18-40 year old aged which is the age range of a machine operator.

The $50^{\text {th }}$ percentile selection was used based on the average person's height on the score. The height dimension of the elbows was used to determine the table height of 99 obtained from the elbow height in the $50^{\text {th }}$ percentile with a score of 97 plus $2 \mathrm{~cm}$ allowance due to the use of the operator footwear. By adjusting the table height with the elbow height, it was expected that the upper arm position would no longer bend too upwards. The length dimension of the forward stretched hands was used to determine the range limits of the tools set on the table to be easily reached by the operator. Furthermore, in redesigning the torque workstation, there was an additional table slope of $15^{\circ}$ to neutralize the neck posture because the operator's head often bent downwards from $15^{\circ}$ to $25^{\circ}$, causing the assessment result of the operator's neck posture reach medium and high levels. To facilitate other operators when there was a job rotation or a new operator coming in, this workstation was made adjustable in which the table height and slope were able to be set accordingly with the work postures of the operator in the workstation so that the postures formed by the operator in work- ing can be suppressed on the neutral condition of workers.

Meanwhile, the other two workstations of the grommet and offline jobs were not redesigned because the grommet workstation had a limited workspace and there was an irremovable expander grommet machine. Almost similarly, the offline workstation also was not changed because it had a limited workspace and the table position had been made tilted by the company.

Three recommendations (wearing gloves, design footrest bar, and redesign workstation /table) as described above can improve the WERA score for torque job (Table 4). Wearing gloves will reduce significantly physical risk of torque job operators on average 4.94-2.94 (reduce equal $40.49 \%$ ). Reducing value is calculated by investigation the contact stress level and wrists posture position from average 59 work elements for torque job. As example, the second work element of torque job for operator 1 before improvement has WERA score - contact stress equal 6 (no gloves, high risk level posture) and after improvement has ERA score - contact stress equal 4 (wearing gloves, high risk level posture, extreme bench). The other WERA score improvement was effected by footrest

TABLE 10. WERA score for torque job after improvement

\begin{tabular}{|l|c|c|c|c|c|c|c|c|c|c|}
\hline \multirow{2}{*}{ Item } & \multicolumn{9}{|c|}{ Risk factor } \\
\cline { 2 - 12 } & $\begin{array}{c}\text { shoul- } \\
\text { der }\end{array}$ & wrist & back & neck & leg & $\begin{array}{c}\text { force- } \\
\text { ful }\end{array}$ & $\begin{array}{c}\text { vibra- } \\
\text { tion }\end{array}$ & $\begin{array}{c}\text { con- } \\
\text { tact } \\
\text { stress }\end{array}$ & $\begin{array}{c}\text { task } \\
\text { dura- } \\
\text { tion }\end{array}$ & $\begin{array}{c}\text { final } \\
\text { score }\end{array}$ \\
\hline Torque 1 & 2.41 & 3.59 & 2.63 & 2.46 & 4.12 & 2.63 & 3.12 & 3.12 & 4.00 & 28.07 \\
\hline Torque 2 & 2.37 & 3.02 & 2.83 & 2.17 & 4.00 & 2.83 & 2.88 & 2.88 & 4.00 & 26.98 \\
\hline Torque 3 & 2.39 & 3.39 & 2.83 & 2.07 & 4.00 & 2.44 & 2.83 & 2.83 & 4.00 & 26.78 \\
\hline Average & 2.39 & 3.33 & 2.76 & 2.23 & 4.04 & 2.63 & 2.94 & 2.94 & 4.00 & 27.28 \\
\hline
\end{tabular}


bar reducing vibration risk factor (vibration level and wrists posture) from 3.01 to 2.94 . The last recommendation is redesign work table, effected on shoulder risk, neck risk. The WERA final score of torque job decreased from 31.23 to 27.28, offline job decreased from 30.93 to 28.93 .

\section{Conclusions}

Here are the conclusions of the data processing, analysis, efforts undertaken and recalculation that has been done in this study:

1. Based on the data processing on torque, grommet and offline jobs conducted using WERA method, the initial results showed that the 3 jobs were at the medium activity level, meaning that these three jobs needed further investigation and changes or improvements. From the calculation of the average score on the three jobs (torque, grommet and offline), it was obtained that the WERA final scores of the torque, grommet and offline operators were respectively 31.23 , 28.87 , and 30.93. Contact stress with a scale of $\geq 4$ was obtained by torque and offline jobs because the operators did not use gloves, affecting the score of this physical risk factor. In contrast, the operator of grommet job used gloves. The risk factors with a scale of 3-4 that were dominant at the three jobs were on the shoulders and neck because the operator's arm posture raised up but still below the chest boundary, and the operator's neck still tended to bend to do the activity.
2. Efforts that the researchers made to reduce the risk of MSDs and decrease the WERA scores in this research were selecting appropriate and convenient gloves for the operators to always be used in working. The proposed gloves are made of foam nitril-coated nylons adjusted to the type of job and have a strong grip. In addition, workstation redesign was also be conducted on the torque job covering the adjustment of the table height, width and slope so that the WERA score of the shoulder and neck risk factors could be reduced. Furthermore, regarding the standing posture, a footrest was added or used so that the operator could rest his legs anytime when he felt leg cramps.

3. Based on the comparison of WERA scores before and after the improvements, the results are concluded good enough on the torque job because the risk factor score in the contact stress, shoulders, and neck decreased from 31.23 to 27.28 . Thus, it can be said that this task or job is acceptable. Moreover, in the offline job, there was also a change (decrease) on the WERA score of the contact stress from 30.93 to 28.93 .

\section{Acknowledgments}

We would like to thank the Ministry of National Education of the Republic of Indonesia for supporting this paper. The authors are also grateful to the Bioengineering research group and also the laboratory of work design and ergonomics, Industrial Engineering Department, Brawijaya University (UB), Malang City, Indonesia for their extraordinary courage. 


\section{References}

Abd Rahman, M.N., Abdul Rani, M.R. \& Rohani, J.M. (2011). WERA: an observational tool develop to investigate the physical risk factor associated with WMSDs. Journal of Human Ergology, 40(1-2), 19-36. Retrieved from: http://www.scopus.com/inward/record. url?eid=2-s2.0-84873402164\&partnerID=tZOtx3y1.

Alexopoulos, E.C., Stathi, I.-C. \& Charizani, F. (2004). Prevalence of musculoskeletal disorders in dentists. BMC Musculoskeletal Disorders, 5(1), 16. doi.org/10.1186/14712474-5-16

Baek, J.H., Kim, Y.S. \& Yi, K.H. (2015). Relationship between Comorbid Health Problems and Musculoskeletal Disorders Resulting in Musculoskeletal Complaints and $\mathrm{Mu}-$ sculoskeletal Sickness Absence among Employees in Korea. Safety and Health at Work, 6(2), 128-133. https://doi.org/10.1016/ j.shaw.2015.03.002

Dianat, I., Haslegrave, C.M. \& Stedmon, A.W. (2014). Design options for improving protective gloves for industrial assembly work. Applied Ergonomics, 45(4), 1208-1217. https://doi.org/10.1016/j.apergo.2014.02.009

Fjell, Y., Alexanderson, K., Karlqvist, L. \& Bildt, C. (2007). Self-reported musculoskeletal pain and working conditions among employees in the Swedish public sector. Work, 28, 33-46. Retrieved from: https:/content.iospress.com/ articles/work/wor00594.

Konz, S. \& Johnson, S. (2004). Work Design: Occupational Ergonomics, $6^{\text {th }}$ ed., Scottsdale, AZ: Holcomb-Hathaway.

Mylon, P.T., Buckley-Johnstone, L., Lewis, R., Carré, M.J. \& Martin, N. (2015). Factors influencing the perception of roughness in manual exploration: Do medical gloves reduce cutaneous sensibility? in Proceedings of the Institution of Mechanical Engineers, Part J: Journal of Engineering Tribology, 229(3), 273-284. https://doi.org/10.1177/135065011 3517111

Shariat, A., Mohd Tamrin, S.B., Arumugam, M., Danaee, M. \& Ramasamy, R. (2016). Office exercise training to reduce and prevent the occurrence of musculoskeletal disorders among office workers: A hypothesis. Malaysian
Journal of Medical Sciences, 23(4), 54-58. https://doi.org/10.21315/mjms2016.23.4.7

Sugiono, S., Soenoko, R. \& Andriani, D. P. (2017). Analysis the relationship of physiological, environmental, and cow milk productivity using AI. In Proceedings of 2016 International Conference on Data and Software Engineering, ICoDSE 2016. https://doi. org/10.1109/ICODSE.2016.7936165

Sugiono, S., Soenoko, R. \& Lukodono, R.P. (2017). A designing dairy cattle facilities based on statics/dynamic zoometry by using artificial intelligence. Telkomnika (Telecommunication Computing Electronics and Control), 15(1). https://doi.org/10.12928/ TELKOMNIKA.v15i1.4677

Tetrick, L.E. \& Peiró, J.M. (2012). Occupational safety and health. In S.W.J. Kozlowski (ed.), The Oxford Handbook of Organizational Psychology. Vol. 2 (pages 1228-1244). East Lansing, MI: Michigan State University. DOI 10.1093/oxfordhb/9780199928286.001.0001

\section{Summary}

Reducing musculoskeletal disorder (MSD) risk of wiring harness workstation using workplace ergonomic risk assessment (WERA) method. Bureau of Labor Statistics in Indonesia notes that musculoskeletal disorder (MSD) is the main category of injury causes in workplaces leading to $30 \%$ compensation costs. The purpose of this paper was to know the risk of work position of wire harness companies using workplace ergonomic risk assessment (WERA) for basic workstation improvements. The first step of this research was studying the literature of MSD, work posture, work position, and WERA. It subsequently proceeded with the identification and assessment process using WERA on each type of wiring harness activity. From the research results, it was obtained three jobs indicated causing muscle injury and soreness namely torque job, grommet job, and offline job. Moreover, the problem was supported by complaints from most workers known by using a discomfort 
survey. Based on the problem, this research was conducted to find out the action levels with WERA method and give improvement recommendation to overcome the problem of musculoskeletal disorders. The results of WERA showed that torque, grommet, and offline jobs needed further investigation and improvement with the scores of 31.23, 28.87, and 30.9. Recommendations were then given in the form of personal protective equipment (PPE) to reduce the risk factor scores on con- tract stress, to provide a new workstation design of torque job, and to add aids for solving other pain problems.

\author{
Authors' address: \\ Sugiono Sugiono, \\ Brawijaya University \\ Faculty of Engineering \\ Department of Industrial Engineering \\ Malang 65145 \\ Indonesia \\ e-mail: sugiono_ub@ub.ac.id
}

